Article

\title{
Isolation and Analytical Method Validation for Phytocomponents of Aqueous Leaf Extracts from Vaccinium bracteatum Thunb. in Korea
}

\author{
Seul-Gi Lee ${ }^{1}$, Haeju Ko ${ }^{1}$, Eun-Jin Choi ${ }^{1}$, Dool-Ri Oh ${ }^{1} @$, Donghyuck Bae ${ }^{1}$ and Chulyung Choi ${ }^{2, *}$ \\ 1 Jeonnam Bioindustry Foundation, Jeonnam Institute of Natural Resources Research (JINR), \\ Jeollanamdo 59338, Korea; thelsg@jbf.kr (S.-G.L.); haejuko3333@jbf.kr (H.K.); eunjinlibe@nate.com (E.-J.C.); \\ pp0806@nate.com (D.-R.O.); bdhyuch@naver.com (D.B.) \\ 2 Department of Biomedical Science, College of Natural Science, Chosun University, Gwangju 61452, Korea \\ * Correspondence: blockstar@hanmail.net; Tel.: +82-62-230-6661; Fax: +82-62-608-5315
}

check for

updates

Citation: Lee, S.-G.; Ko, H.; Choi, E.-J.; Oh, D.-R.; Bae, D.; Choi, C. Isolation and Analytical Method Validation for Phytocomponents of Aqueous Leaf Extracts from Vaccinium bracteatum Thunb. in Korea. Processes 2021, 9, 1868. https:// doi.org/10.3390/pr9111868

Academic Editors: Hsiao-Wei Liao and Guan-Yuan Chen

Received: 24 September 2021

Accepted: 18 October 2021

Published: 20 October 2021

Publisher's Note: MDPI stays neutral with regard to jurisdictional claims in published maps and institutional affiliations.

Copyright: (c) 2021 by the authors. Licensee MDPI, Basel, Switzerland. This article is an open access article distributed under the terms and conditions of the Creative Commons Attribution (CC BY) license (https:// creativecommons.org/licenses/by/ $4.0 /)$.

\begin{abstract}
In this study, major phytochemical compounds of Vaccinium bracteatum Thunb. (VB) aqueous leaf extract were isolated and analyzed using a HPLC-based method, followed by method validation in accordance with the International Conference on Harmonisation (ICH) guidelines for drug development. Five major compounds were isolated in VB extract. Apart from vaccinoside, which had been the only compound isolated in VB extract to date, vanillic acid and protocatechuic acid were isolated for the first time. Isolation of orientin and isoorientin in the VB extract helped validate the reverse-phase analytical method. A new simple and rapid high-performance liquid chromatography (HPLC)-based method was developed for the validation of orientin and isoorientin in VB extract and was determinated according to the ICH guidelines. The analytical method was validated through a Waters Alliance HPLC System containing an e2695 separation module and a 2998 photodiode array (PDA) detector. The VB extract and solutions of orientin and isoorientin were analyzed using a reverse-phase Eclipse XDB-C18 column $(4.6 \times 250 \mathrm{~mm}$ ID, $5 \mu \mathrm{m}$, Waters), which was maintained at $30{ }^{\circ} \mathrm{C}$. A mobile phase of methanol and $0.01 \%$ formic acid in water was used at a flow rate of $1.0 \mathrm{~mL} / \mathrm{min}$ to achieve gradient elution. The linearity of the orientin and isoorientin was excellent results $\left(R^{2} \geq 0.9999\right)$ in the concentration range of $1.0-50.0 \mu \mathrm{g} / \mathrm{mL}$. Precision values ranged $98.55-101.70 \%$ and $98.70-101.18 \%$, respectively. The intra-day and inter-day relative standard deviation (RSD) values of the orientin and isoorientin were all $<2.0 \%$. The average recoveries of orientin ranged $98.30-101.57 \%$, whereas isoorientin ranged $97.81-102.14 \%$ with RSD values $<2.0 \%$. Quantitative analysis found that VB extract contained $2.90 \mathrm{mg} / \mathrm{g}$ of orientin and $3.45 \mathrm{mg} / \mathrm{g}$ of isoorientin.
\end{abstract}

Keywords: Vaccinium bracteatum Thunb.; aqueous leaf extract; isolation; method validation; reversephase HPLC; vaccinoside; orientin; isoorientin

\section{Introduction}

Vaccinium bracteatum Thunb. (VB) is a plant type of the genus Vaccinium (family Ericaceae), which contains over 130 species such as wild blueberry and bilberry. VB is a small taupe twig tree or evergreen shrub with dark purple edible fruits. It is broadly grown in hilly areas of East Asia, specifically in Korea, Japan, and eastern and southern China. VB aqueous leaf extract is used as a traditional herbal medicine to treat several illnesses, such as gonorrhea, vomiting, and skin eruptions [1,2]. Previous studies have described its hypoglycemic [3], tyrosinase [4], anti-inflammatory [5,6], antioxidant [7,8], antimicrobial [9], neuroprotective [5], and anti-diabetic effects [10]. It also has sedative and hypnotic effects [11], enhances spatial learning and memory [12], and provides protection against neuronal damage [13]. 
VB extract contains a range of phytochemical compounds, including flavonoids (e.g., orientin, isoorientin, quercetin, and chrysin) [7,14], coumains (e.g., scopoletin, esculetin) [15], terpenoids (e.g., divaccinosides A-D, vaccinoside) [15], lignans (e.g., lignaniridoid glucoside diesters) [16], and polysaccharides [17]. Secondary plant products, such as flavonoids, terpenoids, and lignans, are important in botanical medicine [18].

A well-known topic in natural pharmaceutical research is the study of flavonoids. Their phenolic components have gained considerable attention because of their physicochemical properties and various pharmacological activities [19-23].

Among flavonoids, orientin and isoorientin, which exist in VB extract, have been studied for their antioxidant, renoprotective [7], antithrombotic, and antiplatelet activities [24]. Flavonoids are of significant importance in the standardization of herbal drugs and nutraceuticals [19-23]. The development and production of pharmaceuticals and functional foods require validation of standardized methods to ensure reliable and repeatable experimental results. According to the guidelines of the International Conference on Harmonisation (ICH), "the objective of validation of an analytical procedure is to prove that it is suitable for its intended purpose". Thus, the processes used during herbal drug and nutraceutical development must be validated. The ICH guidelines have been used previously to validate analysis methods used for this purpose [25,26]. We have previously studied the development of pharmaceuticals with antidepressant-like effects from Vaccinium bracteatum Thunb. (VB) [11-13]. Previous studies employed high-performance liquid chromatography (HPLC) using photodiode array (PDA) detectors for quantification in chlorogenic acid, orientin and isoorientin of VB extract [27]. However, these HPLC methods were not validated for VB extract to standardize VB quality. In this study, major phytochemical compounds of VB aqueous leaf extract were isolated, and the HPLC method was validated in accordance with the ICH guidelines for drug development [25].

\section{Materials and Methods}

\subsection{Plant Materials and Extract}

The VB was obtained from Goheung-gun traditional herbal market (Jeollabuk-do, Korea) and was authenticated by Dr. Chul-yung Choi who belongs to Department of Biomedical Science College of Natural Science, Chosun University, Gwangju, South Korea. The VB specimen was labeled as JINR-VBL006. The VB (600 g) was then crushed and extracted in $12 \mathrm{~L}$ of distilled water (DW) for $3 \mathrm{~h}$ using an oven at $100{ }^{\circ} \mathrm{C}$. The extract was filtered, concentrated under vacuum, and freeze dried. The extracted powder was stored at $4{ }^{\circ} \mathrm{C}$.

\subsection{Isolation and Identification}

The resulting DW extract was partitioned in ethyl acetate. The organic fraction was evaporated in vacuo to yield the residues extracted in ethyl acetate (E.A) (5 g). The E.A fraction ( $5 \mathrm{~g}$ ) was also subjected to silica gel column chromatography (C.C), using a gradient system of Chloroform $\left(\mathrm{CHCl}_{3}\right)$ : Methanol $(\mathrm{MeOH})(10: 1 \rightarrow 1: 1)$, which afforded five subfractions (from E.A 1 to E.A 5). The subfraction E.A 1-3 containing five compounds was isolated by preparative HPLC system with the reverse-phase Optimapack C18 column $(10 \times 250 \mathrm{~mm}, 5 \mu \mathrm{m}$ particle size, RSTech). Each subfraction was analyzed by a gradient solvent system. Preparative HPLC was performed using a Waters Modular HPLC System containing a 2535 quaternary gradient module and 2997 photodiode array (PDA) detector. The diode array detector was used at 254 and $324 \mathrm{~nm}$, and the column temperature was maintained at $35^{\circ} \mathrm{C}$ using a thermostat. Gradient elution was performed by using $\mathrm{MeOH}$ (A) and $0.1 \%$ formic acid in water (B). The gradient elution system for subfraction E.A 1 was as follows: $0-5 \mathrm{~min}, 15 \% \mathrm{~A} ; 10-15 \mathrm{~min}, 20-30 \% \mathrm{~A} ; 15-45 \mathrm{~min}, 30-35 \% \mathrm{~A} ; 45-70 \mathrm{~min}$, 35-40\% A; 70-72 min, 40-100\% A; 72-82 min, 100\% A. E.A 1 yielded $1.4 \mathrm{mg}$ of vanillic acid. The subfraction E.A 2 was subjected to the following gradient solvent system: $0-5 \mathrm{~min}, 15 \%$ A; 10-15 min, 20-30\% A; 15-20 min, 30-35\% A; 20-55 min, 35-40\% A; 55-75 min, 40-45\% A; 75-85 min, 45-100\% A; 85-95 min, 100\% A; protocatechuic acid (2.1 $\mathrm{mg}$ ) was isolated 
from this subfraction. Subfraction E.A 3 was subjected to the following gradient solvent system: 0-5 $\mathrm{min}, 15 \%$ A; $10-15 \mathrm{~min}, 20-30 \%$ A; $15-20 \mathrm{~min}, 30-35 \%$ A; $20-55 \mathrm{~min}, 35-40 \%$ A; $55-75 \mathrm{~min}, 40-45 \%$ A; 75-85 $\mathrm{min}, 45-100 \%$ A; $85-95 \mathrm{~min}, 100 \%$ A; orientin, isoorientin and vaccinoside were isolated from subfraction E.A 3. The flow rate was maintained at $2.0 \mathrm{~mL} / \mathrm{min}$ for subfractions E.A 1 and E.A 2, but it was changed to $2.5 \mathrm{~mL} / \mathrm{min}$ for E.A 3 . The five compounds were separated and purified from the E.A fraction (Figures 1 and 2). These compounds were identified by NMR spectroscopy.

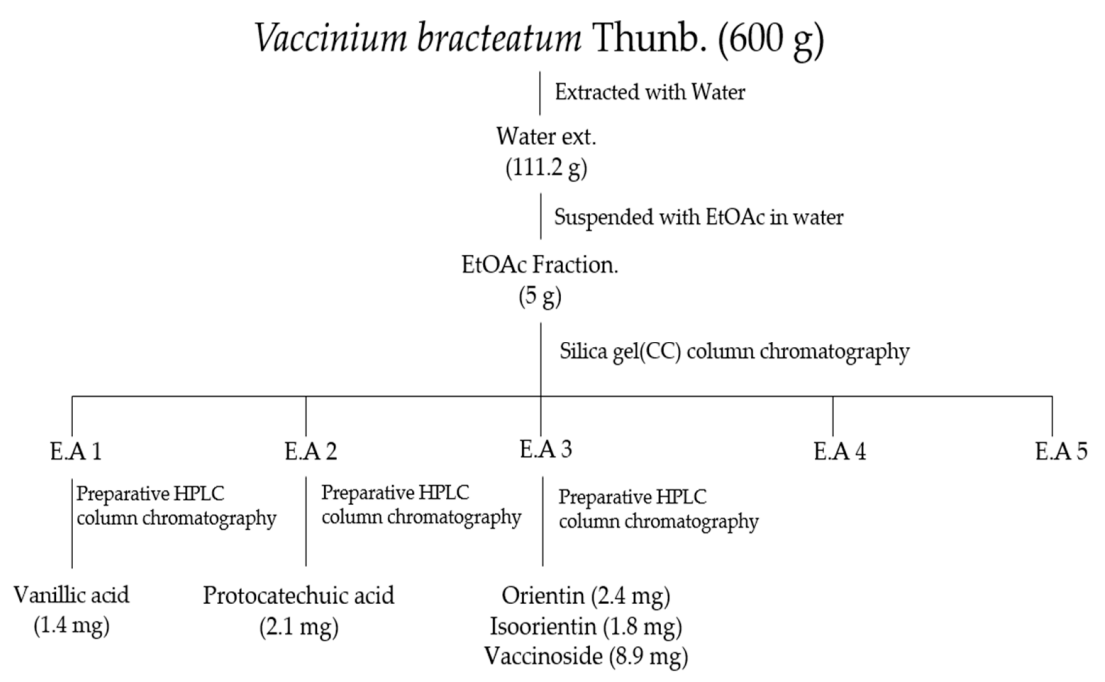

Figure 1. Fractionated process and isolated compounds 1-5 of aqueous leaf extract from Vaccinium bracteatum Thunb. in Korea.<smiles>COc1cc(C(=O)O)ccc1O</smiles>

Vanillic acid (1)<smiles>O=C(O)c1ccc(O)c(O)c1</smiles>

Protocatechuic acid (2)<smiles></smiles>

Orientin (3)<smiles>O=c1cc(-c2ccc(O)c(O)c2)oc2cc(O)c(C3(c4c(O)c(O)cc(O)c4O)O[C@H](CO)[C@@H](O)[C@H](O)[C@H]3O)c(O)c12</smiles>

Isoorientin (4)<smiles>O=C(/C=C/c1ccc(O)cc1)OC[C@]1(O)C=C[C@H]2C(C(=O)O)=CO[C@H](O[C@@H]3O[C@H](CO)[C@@H](O)[C@H](O)[C@H]3O)[C@]21O</smiles>

Vaccinoside (5)

Figure 2. Structures of compounds isolated from Vaccinium bracteatum Thunb. in Korea. 
Vanillic acid (1): FAB-MS m/z: 168 [M] $]^{+}$; IR $v_{\text {MAX }}(\mathrm{MeOH}): 3376,2945,2835,1655,1457$, $1114,683 \mathrm{~cm}^{-1}$ [28].

Protocatechuic acid (3,4-dihydroxybensoic acid) (2): EI-MS $m / z: 154[\mathrm{M}]^{+}$; IR $v_{M A X}$ (KBr): 3214, 1676, 1602, 1529, 1299, 1130, 1097, 942, 765 $\mathrm{cm}^{-1}[29,30]$.

Orientin (3): $m p$ 256-258 ${ }^{\circ} \mathrm{C}$; FAB-MS $m / z: 447$ [M-1]- [31].

Isoorientin (4): mp 180-190 ${ }^{\circ} \mathrm{C}$; FAB-MS $m / z: 449$ [M+H] ${ }^{+}$; IR $v_{\text {MAX }}(\mathrm{MeOH}): 3387$, 2974, 1653, 1456, 1357, 1302, 1054, 1025, $823 \mathrm{~cm}^{-1}$ [28].

Vaccinoside (5): FAB-MS $m / z: 593[\mathrm{M}+\mathrm{Na}]^{+}$; IR $v_{M A X}(\mathrm{MeOH}): 3430,1732,1636$, $1528 \mathrm{~cm}^{-1} ;{ }^{1} \mathrm{H}-\mathrm{NMR}\left(600 \mathrm{MHz}, \mathrm{CD}_{3} \mathrm{OD}\right): \delta 7.67(1 \mathrm{H}, \mathrm{d}, J=13.5 \mathrm{~Hz}, \mathrm{C}-3 "), 7.50(2 \mathrm{H}, \mathrm{dt}, J=4.0$, 7.0, $\left.12.0 \mathrm{~Hz}, \mathrm{H}-6^{\prime \prime}, 9^{\prime \prime}\right), 7.41(1 \mathrm{H}, \mathrm{d}, J=1.5 \mathrm{~Hz}, \mathrm{H}-3), 6.82\left(2 \mathrm{H}, \mathrm{dt}, J=4.0,7.0,12.0 \mathrm{~Hz}, \mathrm{H}-5^{\prime \prime}, 8^{\prime \prime}\right)$, $6.38\left(1 \mathrm{H}, \mathrm{d}, J=13.5 \mathrm{~Hz}, \mathrm{H}-2^{\prime \prime}\right), 6.29(1 \mathrm{H}, \mathrm{dd}, J=2.5,7.0 \mathrm{~Hz}, \mathrm{H}-6), 5.70(2 \mathrm{H}, \mathrm{dds}, J=1.0,5.0 \mathrm{~Hz}$, $\mathrm{H}-1,7), 4.68\left(1 \mathrm{H}, \mathrm{d}, J=\mathrm{Hz}, \mathrm{H}-1^{\prime}\right), 4.34(1 \mathrm{H}, \mathrm{d}, J=9.0, \mathrm{H}-10), 4.22(1 \mathrm{H}, \mathrm{d}, J=9.0 \mathrm{~Hz}, \mathrm{H}-10)$, $3.85\left(1 \mathrm{H}, \mathrm{dd}, J=2.0,8.5 \mathrm{~Hz}, \mathrm{H}-6^{\prime}\right), 3.66\left(1 \mathrm{H}, \mathrm{dd}, J=4.0 \mathrm{~Hz}, \mathrm{H}-6^{\prime}\right), 3.61(1 \mathrm{H}, \mathrm{dq}, J=2.0,5.0 \mathrm{~Hz}$, $\mathrm{H}-9), 2.73(1 \mathrm{H}, \mathrm{dd}, J=2.0,5.0 \mathrm{~Hz}, \mathrm{H}-9) ;{ }^{13} \mathrm{C}-\mathrm{NMR}\left(150 \mathrm{MHz}, \mathrm{CD}_{3} \mathrm{OD}\right): 894.9(\mathrm{C}-1), 152.3(\mathrm{C}-3)$, 111.4(C-4), 46.5(C-5), 138.6(C-6), 133.1(C-7), 84.5(C-8), 39.3(C-9), 70.1(C-10), 170.8(C-11),

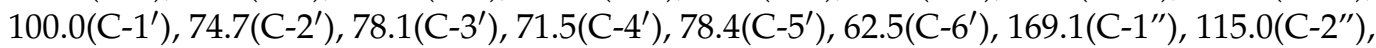
147.1(C-3"), 127.3(C-4"), 115.9(C-5"), 131.4(C-6"), 161.5(C-7"), 115.9(C-8"), 131.4(C-9") [16].

\subsection{Preparation of Extract and Standard Solution}

DW extracted powder was then dissolved in $50 \%$ methanol at a concentration of $10.0 \mathrm{mg} / \mathrm{mL}$. After $10 \mathrm{~min}$ of sonication at room temperature, the solution was filtered using a $0.45 \mu \mathrm{m}$ PTFE syringe filter prior to injection into the HPLC system. Orientin $(\geq 98.0 \%)$ and isoorientin $(\geq 98.0 \%)$ were purchased from Sigma Aldrich Co. (St. Louis, MO, USA). An HPLC grade of methanol solvent and water solvent was employed as the mobile phase (J. T. Baker, Phillipsburg, NJ, USA) with formic acid. Two reference stock solutions were made from orientin and isoorientin. Standards were dissolved in 50\% methanol at a concentration of $50.0 \mathrm{mg} / \mathrm{mL}$. After use in analysis, the two standard solutions were stored at refrigerator temperatures $\left(4^{\circ} \mathrm{C}\right)$.

\subsection{Instrumentation and Analytical Method}

A Waters Alliance HPLC System (Waters Corporation, Milford, MA 01757, USA) containing an e2695 separation module fitted with a 2998 PDA detector was used to validate the liquid chromatography (LC) method. Empower software (Waters) was used for LC data analysis. The mobile phase used methanol (A) and $0.01 \%$ formic acid in water (B). The gradient profile was as follows: 0-5 min, 20\% (A); $5-10 \mathrm{~min}, 20-25 \%$ (A); $10-15 \mathrm{~min}$, $25-28 \%$ (A); $15-22 \mathrm{~min}, 28-35 \%$ (A); $22-27 \mathrm{~min}, 35 \%$ (A) and $27-28 \mathrm{~min}, 100 \%$ (A). The detection wavelength of the reverse-phase Eclipse XDB-C18 column $(4.6 \times 250 \mathrm{~mm}$ ID, $5 \mu \mathrm{m}$ particle size, Waters) was set at $380 \mathrm{~nm}$ for optimized analysis. The operating of the flow rate was maintained at $1.0 \mathrm{~mL} / \mathrm{min}$, the injection volume was $10.0 \mu \mathrm{L}$, and column temperature was set at $30^{\circ} \mathrm{C}$.

\subsection{Method Validation}

The analytical method validation was confirmed according to ICH guidelines [24]. The performance of the method was evaluated by measuring specificity, linearity, limit of detection (LOD), limit of quantitation (LOQ), precision, and recovery.

\subsubsection{Specificity}

Specificity refers to the capability of an analytical method to selectively measure the various components in a complex mixture. Herein, specificity was determined by matching the chromatograms and PDA spectral patterns of standard solutions with that of the VB extract. 


\subsubsection{Linearity and Range}

Standard solutions of orientin and isoorientin with concentrations of 1.0, 5.0, 10.0, 25.0, and $50.0 \mathrm{\mu g} / \mathrm{mL}$ were prepared and analyzed to verify the linearity of the resultant calibration curves. Analysis of standard solutions was repeated three times for each concentration. Linear regression analysis of the eluted peaks was performed, and calibration curves were constructed by peak areas (y) against standard-solution concentrations $(x, \mu \mathrm{g} / \mathrm{mL})$. The correlation coefficients $\left(\mathrm{R}^{2}\right)$ calculated from the calibration curves were used to evaluate the linearity of the relationship.

\subsubsection{LOD and LOQ Calculation}

The LOD of orientin and isoorientin is the minimum amount of these components that can be detected in the VB extract sample. The LOQ is the minimum amount that can be quantitively measured with suitable precision. The LOD and LOQ values were obtained from the standard deviations of the y-intercepts and slopes of the calibration curves. The standard deviations and slopes were calculated from the calibration curves, which were constructed to verify linearity.

\subsubsection{Precision}

The precision of the new method was determined using standard solutions of orientin and isoorientin by inter-day and intra-day experiments at five different concentrations. Intra-day precision was analyzed by executing tests three times a day, and inter-day precision was analyzed by continuing tests three times a day over three successive days. The relative standard deviation (RSD) was calculated to determine precision.

\subsubsection{Recovery}

A recovery analysis was conducted to confirm the accuracy of the proposed method. Recovery was assessed after spiking the VB extract with three concentrations of orientin and isoorientin. Each analysis was repeated three times. Recovery was calculated based on the sample peak area value, standard peak area value, and spiked peak area value.

\section{Results and Discussion}

\subsection{Optimization of HPLC-PDA Condition}

We have discovered orientin and isoorientin to be soluble in methanol; therefore, reversed phase HPLC was the method of choice. By comparing the chromatographic performance of the column of Triart-C18 plus $(4.6 \times 250 \mathrm{~mm}$ ID, $5 \mu \mathrm{m}$ particle size, YMC) with that of the column of Eclipse XDB-C18 $(4.6 \times 250 \mathrm{~mm}$ ID, $5 \mu \mathrm{m}$ particle size, Waters), in the latter, it was shown the effect on shape and resolution of the main chromatographic peaks for an efficient separation of peaks in VB extract. Various combinations of methanol with water or $0.01 \%$ formic acid in water were tried. With an increase in methanol, resolution and peak shapes were improved. A gradient elution system was established by using a column temperature of $30 \pm 2{ }^{\circ} \mathrm{C}$ with a mobile phase of methanol and $0.01 \%$ formic acid in water. UV detection of the standard solutions and VB extracts was carried out using a wavelength range of $200-400 \mathrm{~nm}$. As a result of the interference at lower wavelength, the optimized wavelengths of orientin and isoorientin were determined to be $380 \mathrm{~nm}$ based on a literature survey (Figure 3). In this way, orientin and isoorientin in the VB extract were separated by HPLC analysis. The HPLC-PDA conditions were optimized by varying the mobile phase, column type, column temperature and ultraviolet (UV) detection wavelengths. 

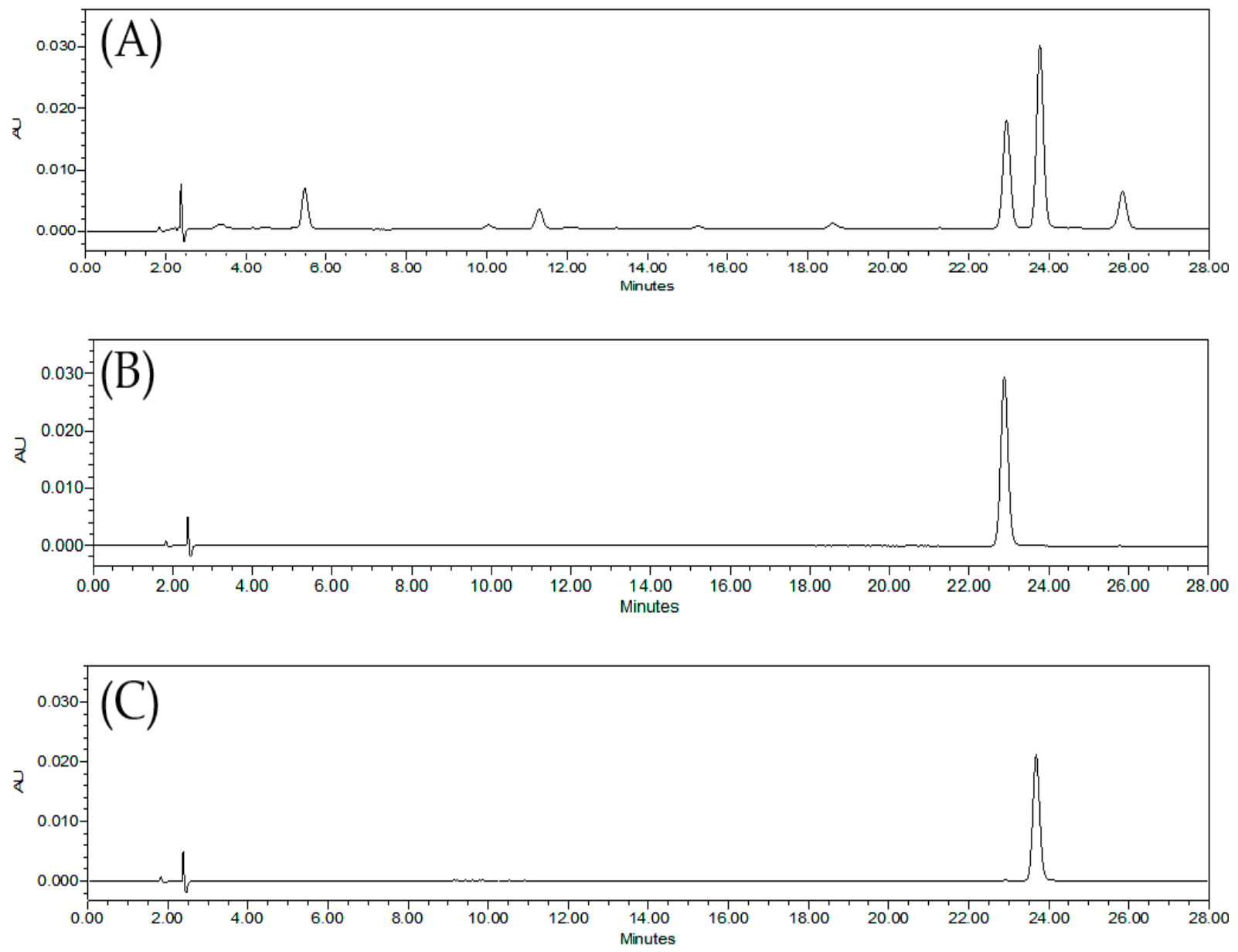

Figure 3. High-performance liquid chromatography chromatograms of (A) Vaccinium bracteatum Thunb. (VB) extract sample, (B) orientin, $(\mathbf{C})$ isoorientin.

\subsection{Method Validation \\ 3.2.1. Specificity}

By comparing the chromatograms of the standard solutions with that of the VB extract sample, it was found that, in the latter, the orientin and isoorientin peaks were well separated and absent of any interference from other components. Specificity was determined by comparing the retention times and PDA spectral patterns of the standard solutions with those of the VB extract samples. The retention times and PDA spectral patterns are shown in Figures 3 and 4.

\subsubsection{Linearity, Range, LOD, and LOQ}

Linearity testing was performed in triplicate by concentration. The experiment of linearity $\left(R^{2} \geq 0.9999\right)$ was observed for orientin and isoorientin of standard solutions in the concentration range of $1.0-50.0 \mu \mathrm{g} / \mathrm{mL}$. By linear regression analysis of orientin(a) and isoorientin(b), the following linear expressions were obtained: $y=7566.6 x-755.11(a)$ and $y=10060 x-985.1(b)$. The LOD values of orientin and isoorientin were 0.008 and $0.002 \mu \mathrm{g} / \mathrm{mL}$, respectively. The LOQs of orientin and isoorientin were 0.025 and 0.005 $\mu \mathrm{g} / \mathrm{mL}$, respectively. 

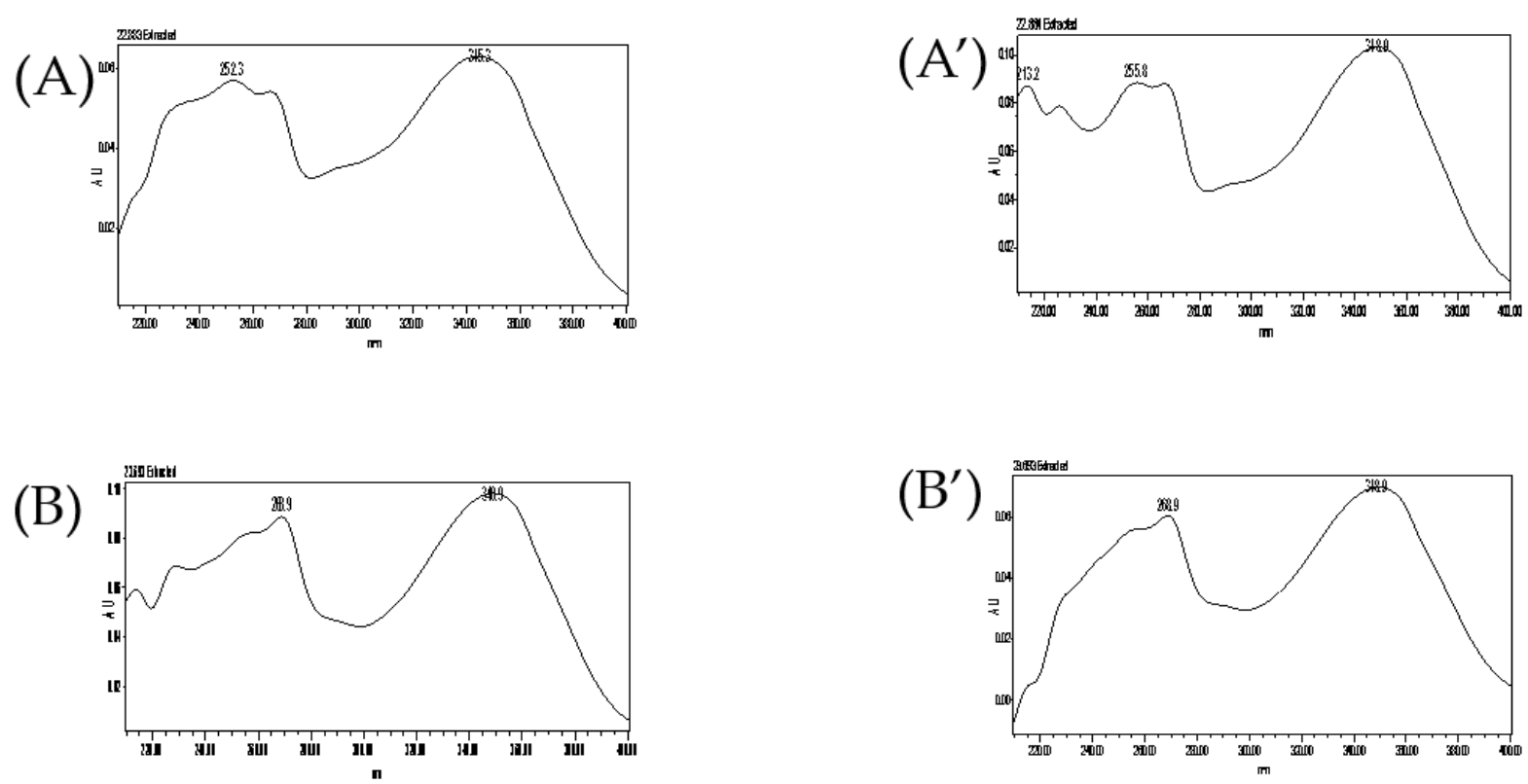

Figure 4. Photodiode array (PDA) spectral patterns were as follows: VB extract sample of (A) orientin and (B) isoorientin; standard solutions of $\left(\mathbf{A}^{\prime}\right)$ orientin and $\left(\mathbf{B}^{\prime}\right)$ isoorientin.

\subsubsection{Precision}

The intra-day and inter-day precision values of standard solutions ranged 98.55$101.70 \%$ and $98.70-101.18 \%$, respectively. The RSDs of orientin and isoorientin were all $<2.0 \%$, ranged $0.043-0.628 \%$ and $0.006-0.076 \%$, respectively (Tables 1 and 2 ). Consequently, the HPLC-PDA analytical method proved reliable and reproducible.

Table 1. Intra-day precision for orientin and isoorientin using the HPLC-PDA method $(n=3)$.

\begin{tabular}{ccccc}
\hline Standard & $\begin{array}{c}\text { Concentration } \\
(\mu \mathrm{g} / \mathbf{m L})\end{array}$ & $\begin{array}{c}\text { Detected } \\
\text { Concentration } \\
(\mu \mathbf{g} / \mathbf{m L})\end{array}$ & $\begin{array}{c}\text { RSD } \\
(\mathbf{\%})\end{array}$ & $\begin{array}{c}\text { Precision } \\
(\mathbf{\%})\end{array}$ \\
\hline \multirow{3}{*}{ Orientin } & 1.00 & 1.02 & 0.302 & 101.70 \\
& 5.00 & 4.93 & 0.392 & 98.55 \\
& 10.00 & 10.07 & 0.112 & 100.66 \\
& 25.00 & 24.99 & 0.212 & 99.97 \\
Isoorientin & 50.00 & 50.00 & 0.045 & 100.00 \\
& 1.00 & 0.99 & 0.047 & 98.75 \\
& 5.00 & 4.93 & 0.072 & 98.69 \\
& 10.00 & 10.08 & 0.029 & 100.80 \\
& 25.00 & 25.02 & 0.045 & 100.06 \\
\hline
\end{tabular}

\subsubsection{Recovery}

The recovery experiment was performed using the HPLC-PDA analytical method by spiking the VB extract samples with standard solutions of orientin and isoorientin. The orientin recoveries ranged $98.30-101.57 \%$, and isoorientin recoveries ranged $97.81-102.14 \%$ with RSD values $<2.0 \%$ (Table 3 ). 
Table 2. Inter-day precision for orientin and isoorientin using the HPLC-PDA method $(n=3)$.

\begin{tabular}{ccccc}
\hline Standard & $\begin{array}{c}\text { Concentration } \\
(\mu \mathrm{g} / \mathbf{m L})\end{array}$ & $\begin{array}{c}\text { Detected } \\
\text { Concentration } \\
(\mu \mathbf{g} / \mathbf{m L})\end{array}$ & $\begin{array}{c}\text { RSD } \\
\mathbf{( \% )}\end{array}$ & $\begin{array}{c}\text { Precision } \\
(\mathbf{\%})\end{array}$ \\
\hline \multirow{3}{*}{ Orientin } & 1.00 & 1.01 & 0.628 & 101.18 \\
& 5.00 & 4.94 & 0.370 & 98.70 \\
& 10.00 & 10.07 & 0.103 & 100.69 \\
& 25.00 & 24.99 & 0.194 & 99.95 \\
Isoorientin & 50.00 & 50.00 & 0.043 & 100.00 \\
& 1.00 & 0.99 & 0.058 & 98.77 \\
& 5.00 & 4.94 & 0.035 & 98.70 \\
& 10.00 & 10.08 & 0.076 & 100.83 \\
& 25.00 & 25.02 & 0.056 & 100.07 \\
\hline
\end{tabular}

Table 3. Recovery study of orientin and isoorientin in VB extract $(n=3)$.

\begin{tabular}{cccccc}
\hline Standard & $\begin{array}{c}\text { Spiked } \\
\text { Concentration } \\
(\mu \mathrm{g} / \mathrm{mL})\end{array}$ & $\begin{array}{c}\text { Detected } \\
\text { Concentration } \\
(\mu \mathrm{g} / \mathrm{mL})\end{array}$ & $\begin{array}{c}\text { Recovery } \\
\mathbf{( \% )}\end{array}$ & SD & $\begin{array}{c}\text { RSD } \\
\mathbf{( \% )}\end{array}$ \\
\hline \multirow{3}{*}{ Orientin } & 1.00 & 30.54 & 101.57 & 0.003 & 0.389 \\
& 5.00 & 34.44 & 98.37 & 0.022 & 0.453 \\
\hline \multirow{3}{*}{ Isoorientin } & 10.00 & 39.35 & 98.30 & 0.082 & 0.837 \\
& 1.00 & 36.05 & 98.43 & 0.011 & 1.168 \\
& 5.00 & 40.06 & 97.81 & 0.008 & 0.172 \\
\hline
\end{tabular}

\subsubsection{Quantitative Analysis of the Two Compounds in VB Extract}

The VB extract was found to contain $2.90 \mathrm{mg} / \mathrm{g}$ of orientin and $3.45 \mathrm{mg} / \mathrm{g}$ of isoorientin. The RSD values of orientin and isoorientin were $0.006 \%$ and $0.484 \%$, respectively (Table 4 ). For quantitative analysis, we developed and verified an analysis method that can quickly quantify orientin and isoorientin by applying a general detection technique of HPLC/UV. As a result of the above analysis, the validity of the analysis of orientin and isoorientin, which are the marker compounds of VB extract for materials used in pharmaceuticals and functional foods, was confirmed.

Table 4. Content of orientin and isoorientin in VB extract $(n=3)$.

\begin{tabular}{ccccc}
\hline Standard & Number & Retention Time & $\begin{array}{c}\text { Content } \\
\text { Average } \\
(\mathbf{m g} / \mathbf{g})\end{array}$ & $\begin{array}{c}\text { RSD } \\
\mathbf{( \% )}\end{array}$ \\
\hline \multirow{2}{*}{ Orientin } & 1 & 22.884 & & \\
& 2 & 22.883 & 2.90 & 0.006 \\
\hline \multirow{2}{*}{ Isoorientin } & 3 & 22.880 & & 0.484 \\
& 1 & 23.693 & 3.45 & \\
\hline
\end{tabular}

\section{Conclusions}

In this study, five compounds were isolated in VB extract. Vaccinoside was the only compound that had previously been identified in VB extract. In this study, vanillic acid and protocatechuic acid were isolated in VB extract for the first time, while the isolation of orientin and isoorientin in VB extract was used to validate the reverse-phase analytical method. In other words, marker compounds of VB aqueous leaf extract were isolated, and the HPLC method was validated in accordance with the ICH guidelines for 
drug development. The improved method utilized a gradient elution system comprising methanol $/ 0.01 \%$ formic acid in water. Analytical method validation was optimized by evaluating the specificity, linearity, LOD, LOQ, precision, and recovery of the process. Quantitative analysis showed that the VB extract contained $2.90 \mathrm{mg} / \mathrm{g}$ of orientin and $3.45 \mathrm{mg} / \mathrm{g}$ of isoorientin. This analytical method for separating the major flavonoids found in VB extract was, therefore, optimized and validated. It could be decided that the suggested methods are reliable, simple, and are expected to be developed further. The findings of the present research are valuable for quality control analysis and standardization of VB extract and can be successfully applied for further flavonoid analysis of blueberry and bilberry or related plant species. The analytical method will hopefully be used for the development of pharmaceuticals with antidepressant-like effects from VB.

Author Contributions: Conceptualization, S.-G.L.; method validation experiments, S.-G.L. and H.K.; writing — original draft preparation, S.-G.L. and H.K.; writing—review and editing, D.-R.O.; visualization, E.-J.C.; project administration, D.B. and C.C.; funding acquisition, C.C. All authors have read and agreed to the published version of the manuscript.

Funding: This research was supported by the Bio and Medical Technology Development Program of the National Research Foundation (NRF) and funded by the Korean government (MSIT) (No. 2019M3A9I3084507).

Acknowledgments: We also express our gratitude to the Korean Basic Science Institute (KBSI), Gwangju Branch, for conducting all the NMR experiments.

Conflicts of Interest: The authors declare no conflict of interest in this research.

\section{References}

1. Song, J.T. The Sauras of Korean Resources Plants II; II-heung: Seoul, Korea, 1989; pp. 48-49.

2. Kim, T.J. Korean Resources Plants III; Seoul National University: Seoul, Korea, 1996; p. 230.

3. Wang, L.; Zhang, Y.; Xu, M.; Wang, Y.; Cheng, S.; Liebrecht, A.; Qian, H.; Zhang, H.; Qi, X. Anti-diabetic activity of Vaccinium bracteatum Thunb. leaves polysaccharide in STZ-induced diabetic mice. Int. J. Biol. Macromol. 2013, 61, 317-321. [PubMed]

4. Kim, M.; Park, J.; Song, K.; Kim, H.G.; Koh, J.-S.; Boo, Y.C. Screening of plant extracts for human tyrosinase inhibiting effects. Int. J. Cosmet. Sci. 2012, 34, 202-208. [CrossRef]

5. Kwon, S.H.; Ma1, S.X.; Ko1, Y.H.; Seo1, J.Y.; Lee, B.R.; Lee, T.H.; Kim, S.Y.; Lee, S.Y.; Jang, C.G. Vaccinium bracteatum Thunb. Exerts Anti-Inflammatory Activity by Inhibiting NF-кB Activation in BV-2 Microglial Cells. Biomol. Ther. 2016, 24, 543-551. [CrossRef]

6. Landa, P.; Skalova, L.; Bousova, I.; Kutil1, Z.; Langhansova, L.; Lou, J.D.; Vanek, T. In vitro anti-proliferative and anti-inflammatory activity of leaf and fruit extracts from Vaccinium bracteatum Thunb. Pak. J. Pharm. Sci. 2014, 27, 103-106.

7. Zhang, J.; Chu, C.J.; Li, X.L.; Yao, S.; Yan, B.; Ren, H.L.; Xu, N.Y.; Liang, Z.T.; Zhao, Z.Z. Isolation and identification of antioxidant compounds in Vaccinium bracteatumThunb. by UHPLC-Q-TOF LC/MS and their kidney damage protection. J. Funct. Foods 2014, 11, 62-67. [CrossRef]

8. Wang, L.; Xu, H.N.; Yao, H.; Zhang, H. Phenolic Composition and Radical Scavenging Capacity of Vaccinium Bracteatum Thunb. Leaves. Int. J. Food. Proper 2011, 14, 721-725. [CrossRef]

9. Zheng, Y.; Chen, L.; Liu, Y.; Shi, L.; Wan, S.; Wang, L. Evaluation of antimicrobial activity of water-soluble flavonoids extract from Vaccinium bracteatum Thunb. leaves. Food. Sci. Biotechnol. 2019, 28, 1853-1859. [CrossRef]

10. Wang, L.; Zhang, X.T.; Zhang, H.Y.; Yao, H.Y.; Zhang, H. Effect of Vaccinium bracteatum Thunb. leaves extract on blood glucose and plasma lipid levels in streptozotocin-induced diabetic mice. J. Ethnopharmacol. 2010, 130, 465-469. [CrossRef]

11. Oh, D.R.; Kim, Y.; Jo, A.; Choi, E.J.; Oh, K.N.; Kim, J.; Kang, H.; Kim, Y.R.; Choi, C. Sedative and hypnotic effects of Vaccinium bracteatum Thunb. through the regulation of serotonegic and GABAA-ergic systems: Involvement of 5-HT1A receptor agonistic activity. Biomed. Pharmacother. 2019, 1, 109. [CrossRef]

12. Oh, D.R.; Kim, Y.; Im, S.; Oh, K.N.; Shin, J.; Jeong, C.; Kim, Y.; Choi, E. Vaccinium bracteatum Improves Spatial Learning and Memory by Regulating N-methyl-D-aspartate Receptors and Tau Phosphorylation in Chronic Restraint Stress-Induced Memory Impaired Mice. Am. J. Chin. Med. 2021, 49, 69-94. [CrossRef] [PubMed]

13. Oh, D.R.; Kim, M.J.; Choi, E.J.; Kim, Y.; Lee, H.S.; Bae, D.; Choi, C. Protective Effects of p-Coumaric Acid Isolated from Vaccinium bracteatum Thunb. Leaf Extract on Corticosterone-Induced Neurotoxicity in SH-SY5Y Cells and Primary Rat Cortical Neurons. Processes 2021, 9, 869. [CrossRef]

14. Wang, L.; Yao, H.Y.; Chen, Z.X. Isolation, Purification and Identification of Flavonoids in Vaccinium bracteatum Thunb. Leaves. Sch. Food. Sci. Technol. 2007, 27, 121-123.

15. Ren, Y.; Chang, Q.K.; Chunping, T.; Yang, Y. Divaccinosides A-D, four rare iridoid glucosidic truxillate esters from the leaves of Vaccinium bracteatum. Tetragedron. Lett. 2017, 58, 2385-2388. [CrossRef] 
16. Ren, Y.M.; Ke, C.Q.; Mandi, A.; Kurtan, T.; Tang, C.; Yao, S.; Ye, Y. Two new lignan-iridoid glucoside diesters from the leaves of Vaccinium bracteatum and their relative and absolute configuration determination by DFT NMR and TDDFT-ECD calculation. Tetrahedron 2017, 73, 3213-3219. [CrossRef]

17. Xu, Q.X.; Shi, J.J.; Zhang, J.G.; Li, L.; Jiang, L.; Wei, Z.J. Thermal, emulsifying and rheological properties of polysaccharides sequentially extracted from Vaccinium bracteatum Thunb leaves. Int. J. Biol. Macromol. 2016, 93, 1240-1252. [CrossRef] [PubMed]

18. Amita, P.; Shalini, T. Concept of standardization, extraction and pre phytochemical screening strategies for herbal drug. J. Pharm. Phytochem. 2014, 2, 115-119.

19. Kumar, S.; Pandey, A.K. Chemistry and Biological Activities of Flavonoids: An Overview. Sci. World J. 2013, $2013,162750$. [CrossRef]

20. Lysiuk, L.; Hudz, N. Differential Spectrophotometry: Application for Quantification of Flavonoids in Herbal Drugs and Nutraceuticals. Int. J. Trends Food. Nutr. 2017, 1, 102.

21. Alzand, K.I.; Mohamed, M.A. Flavonoids: Chemistry, Biochemistry and Antioxidant activity. J. Pharm. Res 2012, 5, 4013-4020.

22. Brodowska, K.M. Natural flavonoids: Classification, potential role, and application of flavonoid analogues. Eur. J. Biol. Res. 2017, 7, 108-123.

23. Jain, P.; Kharya, M.; Gajbhiye, A.; Sara, U.V.S.; Sharma, V.K. Flavonoids as nutraceuticals. A review. Herba Polonica 2010, 56, 105-117.

24. Lee, W.H.; Bae, J.S. Antithrombotic and antiplatelet activities of orientin in vitro and in vivo. J. Func. Food 2015, 17, 388-398 [CrossRef]

25. International Council for Harmonisation (ICH). Validation of Analytical Procedures: Text and Methodology Q2(R1). In Proceedings of the International Conference on Harmonisation of Technical Requirements for Registration of Pharmaceuticals for Human Use, Geneva, Switzerland, 1 November 2005.

26. Chandran, S.; Singh, R.S.P. Comparison of various international guidelines for analytical method validation. Pharmazie 2007, 62, 4-14.

27. Oh, D.R.; Yoo, J.S.; Kim, Y.; Kang, H.; Lee, H.; Lim, S.J.; Choi, E.; Jung, M.A.; Bae, D.H.; Oh, G.N.; et al. Vaccinium bracteatum Leaf Extract Reverses Chronic Restraint Stress-Induced Depression-Like Behavior in Mice: Regulation of Hypothalamic-PituitaryAdrenal Axis, Serotonin Turnover Systems, and ERK/Akt Phosphorylation. Front. Pharmacol. 2018, 9, 604. [CrossRef] [PubMed]

28. Chang, S.W.; Kim, K.H.; Lee, I.K.; Choi, S.U.; Ryu, S.Y.; Lee, K.R. Phytochemical Constituents of Bistorta manshuriensis. Nat. Prod. Sci. 2009, 15, 234-240.

29. Kikuzaki, H.; Kawai, Y.; Nakatani, N. 1,1-Diphenyl-2-picrylhydrazyl Radical-scavenging Active Compounds from Greater Cardamon (Amomum subulatum Roxb.). J. Nutr. Sci. Vitaninol. 2001, 47, 167-171. [CrossRef]

30. An, L.J.; Guan, S.; Shi, G.F.; Bao, Y.M.; Duan, Y.L.; Jiang, B. Protocatechuic acid from Alpinia oxyphylla against MPP ${ }^{+}$-induced neurotoxicity in PC12 cells. Food Chem. Toxicol. 2006, 44, 436-443. [CrossRef]

31. Wang, R.-F.; Yang, X.-W.; Ma, C.-M.; Liu, H.-Y.; Shang, M.-Y.; Zhang, Q.-Y.; Cai, S.-Q.; Park, J.-H. Trollioside, a new compound from the flowers of Trollius chinensis. J. Asian Nat. Prod. Res. 2004, 6, 139-144. [CrossRef] [PubMed] 